\title{
Biocompuesto bicapa incorporado con nisina: caracterización y eficacia contra Escherichia coli
}

\author{
Karen. S. Muñoz-Pabon, Carlos A. González-Callejas, y Héctor. S. Villada-Castillo \\ Facultad de Ciencias Agrarias, Dpto. de Agroindustria. Univ. del Cauca, Cl. 5 \# 4-70, Popayán, Colombia \\ (correo-e: kspabon@unicauca.edu.co; cgonzalezcallejas@unicauca.edu.co; villada@unicauca.edu.co)
}

* Autor a quien debe ser dirigida la correspondencia

Recibido Jun. 25, 2021; Aceptado Ago. 26, 2021; Versión final Oct. 6, 2021, Publicado Feb. 2022

\begin{abstract}
Resumen
El objetivo de esta investigación fue desarrollar un biocompuesto activo (BA) bicapa a partir de afrecho de yuca, fique y glicerol más un recubrimiento de ácido poliláctico (PLA) y nisaplin $\circledast$, que permitiera su implementación en matrices alimentarias de alta humedad. Se evaluaron sus propiedades mecánicas, térmicas, absorción de agua y efecto antimicrobiano sobre Escherichia coli. Se realizó un diseño experimental unifactorial completamente al azar, con cuatro concentraciones de nisina. La prueba de flexión indicó que la adición de PLA y nisina no tuvo efecto significativo sobre el esfuerzo ni sobre el módulo de flexión. El análisis térmico por calorimetría de barrido diferencial (DSC) resultó en dos máximos endotérmicos, uno exotérmico y uno de transición vítrea. El ensayo de absorción de agua en el BA indicó un porcentaje del $35 \%$. Se concluye que el BA no tiene efecto inhibitorio sobre E. coli, pero tiene potencial de aplicación en alimentos con alta humedad.
\end{abstract} agua

\section{Nisin-incorporated bilayer biocomposite: characterization and efficacy against Escherichia coli}

\begin{abstract}
The main objective of this research study was to develop a bilayer active biocomposite (BA) from cassava bran, fique, and glycerol with a coating of polylactic acid (PLA) and nisaplin ${ }^{\circledR}$ that would allow its implementation in high humidity food matrices. Mechanical and thermal properties, water absorption, and antimicrobial effect on Escherichia coli were evaluated. A one-factorial completely randomized experimental design was performed with four concentrations of nisin. The flexural test revealed that the addition of PLA and nisin had no significant effect on stress or flexural modulus. Thermal analysis by differential scanning calorimetry (DSC) resulted in two endothermic peaks, one exothermic peak, and one glass transition peak. The BA's water absorption test had a percentage of $35 \%$. It is concluded that the BA had no inhibitory effect on $E$. coli, but showed promissory potential for its application in high humidity foods.
\end{abstract}

Keyword: polylactic acid; agro-industrial waste; flexural properties; thermal analysis; water absorption 


\section{INTRODUCCIÓN}

El mercado mundial de alimentos siempre ha ido cambiando y adaptándose según la evolución económica y social, prueba de ello, es el auge en el sector de los supermercados, un formato minorista que requiere alimentos libres de patógenos y de buena calidad durante su periodo de almacenamiento. Esto sugiere un reto para los empaques, que es donde permanecen los productos alimenticios durante su exhibición en anaquel. En los últimos años se han producido avances notables en la producción de películas de embalaje polimérico y comestible con incorporación de compuestos antimicrobianos para su uso en alimentos (Zhong et al., 2020), que permiten una interacción con la matrices alimentarias, transfiriendo propiedades antimicrobianas o antioxidantes.

Para cumplir con este requerimiento y con la tendencia de los consumidores por productos naturales, sin conservantes artificiales y que no afecten el medio ambiente, se han presentado estudios sobre la incorporación de conservantes naturales, tales como bacteriocinas, quitosano, enzimas, extractos de plantas y algunos metales, en biopolímeros como el ácido poliláctico (PLA), que es un polímero biodegradable y compostable (Tawakkal et al., 2014). Entre las bacteriocinas está la nisina, una bacteriocina producida por Lactococcus lactis ssp, autorizada por la Food and Drug Administration en 1988 (FDA, 1988), y utilizada como un bioconservante en 57 países de todo el mundo, se usa comercialmente en una variedad de alimentos, lácteos, huevos, verduras, carne, pescado, bebidas y productos a base de cereales; debido a que no es tóxica, es termoestable y no transfiere malos sabores (Biswaro et al., 2018). De acuerdo con estudios realizados la nisina ha demostrado tener un efecto inhibitorio contra microorganismo seleccionados tales como Listeria monocytogenes (Salmieri et al., 2014) , Escherichia coli, Staphylococcus aureus (dos Santos et al., 2018).

Además de los estudios sobre agentes antimicrobianos y biodegradables, en la elaboración de empaques, se viene investigando sobre la aplicación de desechos celulósicos y subproductos del agro, como fuente de relleno, que representa una forma atractiva y sostenible de valorización, algunas de las ventajas de las fibras vegetales son su abundancia natural, baja densidad, alta rigidez específica y biodegradabilidad, sin embargo su alta permeabilidad al agua e inestabilidad térmica son sus principales inconvenientes para aplicaciones como rellenos de plástico (George et al., 2016). Aspecto por el cual es necesario probar alternativas bicapa, que permitan mejorar las propiedades de barrera al agua, de esta menara ampliar su aplicación en sistemas alimentarios que presentan alta humedad.

Diferentes estudios sobre biocompuestos basados en fibras naturales se pueden encontrar en la literatura científica, tales como residuos de arroz, almendra, pastos de mar (Sánchez-safont et al., 2018), se ha explorado el fique (Cajiao et al., 2016), residuos de café (Tan et al., 2017) entre otros. Cambiar biocompuestos lignocelulosos con materiales renovables como el ácido poliláctico (PLA) es una opción para mejorar las deficiencias de las fibras e incorporar agentes activos. Li et al. (2012), realizaron un compuesto de remolacha recubierto con PLA, quitosano y isotiocianato de alilo para inactivar Salmonella. El objetivo de la presente investigación fue desarrollar un recubrimiento anti-microbiano a partir de PLA, nisina comercial, para su aplicación directa sobre una bandeja semirrígida biodegradable y generar un empaque activo, con potencial uso en alimentos perecederos. Se efectuaron pruebas microbiológicas del empaque activo a diferentes concentraciones de antimicrobianos, se incubo E. coli para medir el efecto antimicrobiano. Se evaluaron las propiedades mecánicas, térmicas y absorción de agua en la bandeja recubierta.

\section{METODOLOGÍA}

La elaboración del biocompuesto activo se realizó a través de la mezcla de fibras y harina de yuca, la cual se recubrió con una capa de PLA, donde se adicionó nisinaplin® comercial. La caracterización se llevó a cabo por medio de pruebas físicas y térmicas.

\section{Materiales}

Harina integral de yuca variedad HMC-1, suministrada por la Corporación CLAYUCA. (Valle del Cauca) Cali, Colombia. Fibra de fique molida variedad Uña de Águila, proporcionado por la Cooperativa de Productores de Paniquita (Cauca, Colombia). Ácido poliláctico (Referencia 4032D) suministrado por Cargill Dow Polymers LLC (USA). Glicerol grado analítico (99.5\% de pureza), provisto por DISAN S.A (Cali-Colombia), nisina comercial suministrada por CIMPA (Bogotá-Colombia). Agar Caldo Infusión Cerebro Corazón (BHI) (Sharlau, España), Microorganismo para desafío Escherichia coli ATCC 25922, provista por ceparios von Hunbolt del grupo de investigación Microbiología y Biotecnología aplicada (MIBIA) de la Universidad del Valle.

\section{Elaboración de los biocompuesto}

Se gelatinizó harina de yuca calentando en plancha (Thomas Scientific, USA) una suspensión de la harina en agua al $20 \%$ (en base seca) a una temperatura de $67^{\circ} \mathrm{C}$, bajo agitación manual constante. Posteriormente se preparó una mezcla incorporando $30 \%$ de fibra de fique y $5 \%$ de glicerol con base en el peso de la harina de yuca gelatinizada. Dicha mezcla se sometió a moldeo en una máquina de compresión hidráulica (EDAFA, Medellín, Colombia) a temperatura de $200{ }^{\circ} \mathrm{C}$ durante $3 \mathrm{~min}$, bajo una presión de $6,89 \mathrm{MPa}$ (Cajiao et al., 2016). 


\section{Preparación de recubrimiento y adición de capa de PLA}

El recubrimiento se prepara según metodología descrita por Jin et al. (2010). Se pesaron $2 \mathrm{~g}$ de PLA y cuatro concentraciones de nisaplin $₫$, que se definieron de acuerdo a la metodología de Bastarrachea et al. (2010), en la tabla 1 se presentan las formulaciones que se emplearon, por separado se prepararon las diferentes concentraciones en un beaker adicionando $30 \mathrm{~mL}$ de cloruro de metileno. Posteriormente cada formulación se mezcló hasta que se disolvió totalmente el PLA. El biocompuesto moldeado fue recubierto mediante inmersión para asegurar la total adhesión del mismo, luego se colocó en cámara de flujo para que se volatilice el solvente a una temperatura de $35^{\circ} \mathrm{C}$, durante $50 \mathrm{~min}$.

Tabla 1. Formulación de biocompuesto con efecto antimicrobiano. BA: Biocompuesto Activo; NISN: Nisina

\begin{tabular}{|l|c|}
\hline $\begin{array}{l}\text { Códigos para tratamientos } \\
\text { de biocompuesto }\end{array}$ & Nisina \\
\hline BANISN1 & $1000 \mathrm{UI}$ \\
\hline BANISN2 & $2000 \mathrm{UI}$ \\
\hline BANISN3 & $3000 \mathrm{UI}$ \\
\hline BANISN4 & $4000 \mathrm{UI}$ \\
\hline BCONTROL & - \\
\hline
\end{tabular}

Medición de la resistencia a la flexión del material

Se evaluó la resistencia a la flexión del BA obtenido siguiendo la metodología definida por la norma D790-10, empleando una máquina universal de ensayos (EZ-L, Shimadzu, Japan). Las matrices fueron moldeadas en forma de muestras planas de $50,8 \mathrm{~mm}$ de largo $12,7 \mathrm{~mm}$ de ancho y de $1,5 \mathrm{~mm}$ de espesor. Previamente a la prueba, las muestras fueron acondicionadas durante 8 días a una humedad relativa de $50 \pm 10 \%$ y una temperatura de $23 \pm 2{ }^{\circ} \mathrm{C}$, las mediciones para cada replica se registraron 15 veces.

\section{Análisis por calorimetría de barrido diferencial (DSC)}

Se cortó una porción de los diferentes BA a analizar, entre $4 \mathrm{mg}$ a $5 \mathrm{mg}$, se encapsuló en cápsula de aluminio con cierre hermético y se introdujo al calorímetro de barrido diferencial (DSC Q20, TA Instruments, USA), en el cual la muestra se sometió a un rango de temperatura desde $-60^{\circ} \mathrm{C}$ hasta $250^{\circ} \mathrm{C}$ a una velocidad de 20 ${ }^{\circ} \mathrm{C} / \mathrm{min}$. Se determinó la temperatura de fusión y entalpía de fusión de las matrices moldeadas. El grado de cristalinidad $\left(\mathrm{X}_{\mathrm{C}}\right)$ se determinó de acuerdo con la Ecuación 1.

$$
X_{C}=\left(\frac{\Delta \mathrm{H}}{\Delta \mathrm{H}_{m}^{\circ} *\left(1-\frac{\% \omega t B S R}{100}\right)}\right) * 100
$$

\section{Análisis termo gravimétrico (TGA)}

La degradación de los componentes se estudió en un analizador termogravimétrico (TGA 2050TA Instruments, USA). Los ensayos se efectuaron a velocidad de calentamiento de $20^{\circ} \mathrm{C} / \mathrm{min}$ entre $30-500^{\circ} \mathrm{C}$ con muestras de $5 \mathrm{mg}$ de peso aproximadamente, de acuerdo con la norma Standard Test Method for Compositional Analysis by Thermogravimetry (ASTME1131-08). Esta prueba se aplicó para determinar la temperatura de degradación térmica del biocompuesto.

\section{Medición de análisis de absorción de agua}

La prueba de absorción de agua se realizó según la metodología proporcionada por la norma ASTM D57010. Las muestras recubiertas y sin recubrir se secaron a una temperatura de $50 \pm 3{ }^{\circ} \mathrm{C}$ durante $24 \mathrm{~h}$, transcurrido el tiempo de secado, se dejaron enfriar en desecador hasta temperatura ambiente, se registró su peso inicial en una balanza analítica (RADWAG XA 110/X, Polonia) y se sumergieron en agua potable a $23 \pm 1$ ${ }^{\circ} \mathrm{C}$ durante $2 \mathrm{~h}$, después se secó la superficie de cada muestra y se registró su peso. Finalmente, los especímenes se sometieron a un segundo secado a $50 \pm 3{ }^{\circ} \mathrm{C}$ durante $24 \mathrm{~h}$ y se pesaron nuevamente. Los cálculos se realizaron así: El incremento de peso de la muestra por la inmersión (IP) expresado en porcentaje, está dado por la ecuación (2) y el porcentaje de materia soluble perdida (MSP) está dado por la ecuación (3). 


$$
\begin{aligned}
& \% I P=\frac{(P H-P A)}{P A} * 100 \\
& \% M S P=\frac{(P A-P R A)}{P A} * 100
\end{aligned}
$$

El valor de absorción de agua en porcentaje se tomó como la suma del incremento del peso de la muestra por la inmersión en porcentaje y del porcentaje de material soluble perdido.

\section{Preparación del inoculo}

Las cepas liofilizadas Escherichia coli ATCC 25922, fueron suministradas por la Colección Colombiana de Cultivos Tipo (ATCC, Universidad del Valle, Colombia), y se almacenaron a $-25^{\circ} \mathrm{C}$ con $30 \%$ de glicerol. Los cultivos bacterianos en fase de crecimiento exponencial se prepararon inoculando las suspensiones de reserva microbianas en caldo soya tripticasa CST, seguido de su incubación a $35{ }^{\circ} \mathrm{C}$ durante $12 \mathrm{~h}$ en incubadora (BD 115 Binder, Alemania), hasta obtener suspensiones bacterianas de 10 $0^{4-5} \mathrm{UFC} / \mathrm{mL}$.

\section{Medición del Análisis microbiológico del empaque}

La inhibición bacteriana de los BA se evaluó utilizando un método de difusión en agar como lo describe Jin \& Zhang, (2008). Cada muestra $(1 \times 1 \mathrm{~cm})$ fue colocada en la superficie de una placa de agar BHI semiblando sembrado. La densidad de la bacteria fue de aproximadamente $10^{4-5} \mathrm{UFC} / \mathrm{mL}$ de Escherichia coli. Las placas se incubaron a $37^{\circ} \mathrm{C}$ durante $24 \mathrm{~h}$. Diámetros de la zona de inhibición se midieron con pie de rey (Mitutoyo Electronic Digital Caliper 500-196-30, Japón) alrededor de la muestra de película se usaron para determinar la actividad antimicrobiana de cada muestra de BA. Se emplearon como control positivo discos de gentamicina.

\section{Análisis estadístico}

Los resultados se expresaron como medias \pm desviación estándar, $n=3$ para las mediciones de flexión, $n=5$ para las mediciones de absorción de agua, $n=3$ para los ensayos de inhibición antimicrobiana, $n=2$ para las muestras de DSC y TGA, esta prueba solo se hizo para el BANISN4. Se utilizó ANOVA unifactorial completamente al azar, para evaluar el efecto de la aplicación de la capa de PLA y nisaplin ${ }^{\circ}$, evaluando cuatro concentraciones. Se utilizó un nivel de significancia $\alpha=0,05$. Se realizó una prueba post hoc de Dunnett, que permite comparar los tratamientos con el control, BCONTROL sin nisaplin $®$. Los análisis fueron realizados en el programa estadístico Minitab V 18.

\section{RESULTADOS Y DISCUSIÓN}

A continuación, se presentan los resultados de las pruebas mecánicas, térmicas y de inhibición. Esto se hace en cuatro secciones, para mayor claridad: propiedades de flexión, análisis térmico, absorción de agua, y análisis microbiológico

\section{Propiedades de flexión}

Los resultados obtenidos de la prueba de flexión, muestran que las concentraciones de nisina no tienen efecto significativo sobre el máximo esfuerzo de flexión, ni sobre el módulo de flexión $(p>0,05)$, para la elasticidad si hay un efecto significativo $(p<0,05)$. La tabla 2 muestra los valores de flexión de las diferentes muestras, se reportan valor promedio \pm desviación estándar. Superíndices diferentes en la misma columna indican diferencias significativas $(p<0,05)$. En la tabla 3 se presentan los valores estadísticos del análisis de varianza.

Tabla 2: Propiedades mecánicas de flexión de las muestras moldeadas.

\begin{tabular}{|c|c|c|c|}
\hline Biocompuesto & Esfuerzo máximo en flexión MPa & Elasticidad (\%) & Módulo máximo en flexión MPa \\
\hline BCONTROL & $19,60 \pm 0,69$ & $2,98 \pm 0,15^{\mathrm{b}}$ & $1157,62 \pm 47,32$ \\
\hline BANISN1 & $20,52 \pm 1,33$ & $3,8 \pm 0,47^{\mathrm{a}}$ & $976,92 \pm 21,25$ \\
\hline BANISN2 & $17,70 \pm 1,71$ & $3,1 \pm 0,05^{\mathrm{a}}$ & $946,76 \pm 93,17$ \\
\hline BANISN3 & $19,47 \pm 0,53$ & $2,77 \pm 0,28^{\mathrm{b}}$ & $1075,40 \pm 16,33$ \\
\hline BANISN4 & $19,55 \pm 3,79$ & $2,44 \pm 0,19^{\mathrm{b}}$ & $1242,24 \pm 285,22$ \\
\hline
\end{tabular}

\begin{tabular}{|c|c|c|c|c|c|c|c|c|c|c|c|c|}
\hline \multicolumn{5}{|c|}{ Esfuerzo de flexión } & \multicolumn{4}{|c|}{ Elasticidad } & \multicolumn{4}{|c|}{ Módulo máximo en flexión } \\
\hline Fuente & $\begin{array}{c}\text { SC } \\
\text { Ajust }\end{array}$ & $\begin{array}{c}\text { MC } \\
\text { Ajust }\end{array}$ & $\begin{array}{c}\text { Valor } \\
\mathrm{F}\end{array}$ & $\begin{array}{c}\text { Valor } \\
p\end{array}$ & $\begin{array}{c}\text { SC } \\
\text { Ajust }\end{array}$ & $\begin{array}{c}\text { MC } \\
\text { Ajust }\end{array}$ & $\begin{array}{c}\text { Valor } \\
\mathrm{F}\end{array}$ & $\begin{array}{c}\text { Valor } \\
p\end{array}$ & $\begin{array}{c}\text { SC } \\
\text { Ajust }\end{array}$ & $\begin{array}{c}\text { MC } \\
\text { Ajust }\end{array}$ & $\begin{array}{c}\text { Valor } \\
\mathrm{F}\end{array}$ & $\begin{array}{c}\text { Valor } \\
\mathrm{p}\end{array}$ \\
\hline Tratamiento & 12,66 & 3,16 & 0,8 & 0,554 & 3,02 & 0,75 & 10,29 & 0,001 & 182243 & 45561 & 2,45 & 0,114 \\
\hline Error & 39,73 & 3,97 & & & 0,73 & 0,07 & & & 185972 & 18597 & & \\
\hline Total & 52,39 & & & & 3,75 & & & & 368215 & & & \\
\hline
\end{tabular}

Tabla 3: Análisis de varianza de las propiedades mecánicas 
De acuerdo con Cajiao et al. (2016) en biocompuestos realizados a partir de fique y harina de yuca sin aplicación de PLA, se obtuvieron valores de esfuerzo máximo de flexión de 15,5 MPa, es decir que la adición de la capa de ácido poliláctico genera un incremento de 5,02 MPa comparándolo con el BANISN1, esto se debe posiblemente a una adhesión interfacial entre fibra y matriz. El polímero de PLA puede tener contacto y transferir estrés a la fibra, es decir que el almidón que contiene la harina de yuca, actúa en presencia de calor con la molécula agua y del glicerol, formado una matriz termoplástica hidrofílica que puede interactuar con la hidrofilia de PLA (grupos éster) (Yew et al., 2005). Según lo anterior el biocompuesto activo BANISN1 presentó un esfuerzo de flexión de aproximadamente $24 \%$ mayor, con respecto al biocompuesto sin PLA, este incremento es bajo teniendo en cuenta el alto nivel de resistencia que presenta el PLA puro, cerca de $75 \mathrm{MPa}$ (Campaña et al., 2018). Esto se puede explicar debido a que el porcentaje de fibra y almidón en la matriz del biocompuesto es del $80 \%$ y el contenido de PLA del $20 \%$, según lo reporta (Rajesh et al., 2016) la adición de PLA en diferentes fibras puede aumentar el esfuerzo de flexión, sin embargo, cuando los contenidos de fibra son superiores al $20 \%$ en la mezcla, la propiedades de flexión caen.

\section{Análisis térmico DSC y TGA}

Se evaluaron propiedades térmicas al BA que contenía la mayor concentración de nisaplin $®$. Las propiedades térmicas de la muestra BANISN4 fueron determinadas por DSC. Las transiciones térmicas en mezclas son usuales para determinar las interacciones entre los componentes. En la Tabla 4 se presentan los diferentes valores de los picos térmicos, se puede observar que la temperatura de transición vítrea ( $\mathrm{Tg})$ del PLA puro se reduce en el $\mathrm{BA}$, decrece de $56,9^{\circ} \mathrm{C}$ a $54,95^{\circ} \mathrm{C}$, asimismo la entalpia de fusión endotérmico $(\Delta \mathrm{Hm})$ y exotérmico de cristalinidad $(\Delta \mathrm{Hc})$ se reducen en la mezcla del biocompuesto, los valores de la temperatura de cristalización (Tc) y la temperatura de fusión (Tm) caen en el BA. Una reducción en Tm ocurre cuando un componente semicristalino (PLA) es miscible en un polímero amorfo (almidón) (Martin \& Avérous, 2001), aspecto que sugiere un grado de miscibilidad entre los polímeros. La figura 1 muestra que en el segundo calentamiento, se presenta un pico de fusión de hombro justo antes del pico de fusión principal $\operatorname{Tm}_{1}$ y $\operatorname{Tm}_{2}$, respectivamente. Cada pico de fusión es la firma de una población de laminillas cristalinas caracterizadas esencialmente por su grosor o su perfección, el pico de fusión a temperatura más alta ( $\left.\mathrm{Tm}_{2}\right)$ podría atribuirse a un estructura cristalina más perfecta de PLA y el pico del hombro en temperatura más baja $\left(\operatorname{Tm}_{1}\right)$ a una estructura cristalina más desordenada (Frone et al., 2013).

Este comportamiento también fue reportado por Battegazzore et al. (2014), en biocompuesto elaborados a partir de fibras y PLA. El porcentaje de cristalinidad (Xc) disminuye en el BANISN4, es decir que la estructura de la muestras es menos rígida, más flexible y por lo tanto más fácil de procesar que el PLA puro (Anuar et al., 2017). En la figura 2 se observa la degradación térmica del BA, la cual se llevó a cabo principalmente en dos etapas.

Tabla 4: Propiedades térmicas derivadas de la segunda exploración de calentamiento. BANISN4: Biocompuesto activo/nisina4

\begin{tabular}{|c|c|c|c|c|c|c|c|}
\hline Compuesto & $\operatorname{Tg}\left({ }^{\circ} \mathrm{C}\right)$ & $\operatorname{Tc}\left({ }^{\circ} \mathrm{C}\right)$ & $\Delta \mathrm{Hm}$ & $\operatorname{Tm} 1\left({ }^{\circ} \mathrm{C}\right)$ & $\operatorname{Tm} 2\left({ }^{\circ} \mathrm{C}\right)$ & $\Delta \mathrm{Hc}$ & $\mathrm{Xc}(\%)$ \\
\hline PLA $^{*}$ & 56,9 & 151,5 & 23,6 & 168,1 & - & 36,2 & 38,9 \\
\hline BANISN4 & 54,95 & 111,8 & 6,013 & 159,86 & 166,77 & 8,404 & 17,29 \\
\hline
\end{tabular}

Para el análisis de TGA, inicialmente, se evidencia una ligera pérdida de peso alrededor de $61,98^{\circ} \mathrm{C}$, probablemente debido a la pérdida de moléculas de agua unidas a través de enlaces de hidrógeno a componentes hidrofílicos, como el almidón, fibras de fique. En la segunda etapa inicia la degradación de cadenas de compuestos de la nisina (Saini et al., 2016). Se observó una mayor degradación térmica (pérdida de peso del $68,44 \%$ ) entre 200 y $322,05^{\circ} \mathrm{C}$, esta segunda etapa refleja la pérdida y la degradación de la PLA (Plackett et al., 2006). La despolimerización de la amilosa, que caracteriza el comienzo de la degradación térmica del almidón, probablemente también ocurre en esta etapa (Bhat et al., 2013).

\section{Absorción de agua}

En la tabla 5 se muestran los resultados de la prueba de absorción de agua, según el análisis estadístico el recubrimiento de PLA y nisina influye significativamente sobre el paso de agua $(p<0,05)$. El biocompuesto control presenta un porcentaje de absorción de agua del 145,29 \%, cuatro veces más alta que el BANISN4, las fibras naturales son altamente hidrofílicas, debido a los grupos hidroxilos de los polisacáridos encontrados en la celulosa, que pueden forman puentes de hidrogeno con el agua (Santiagoo et al., 2011). 


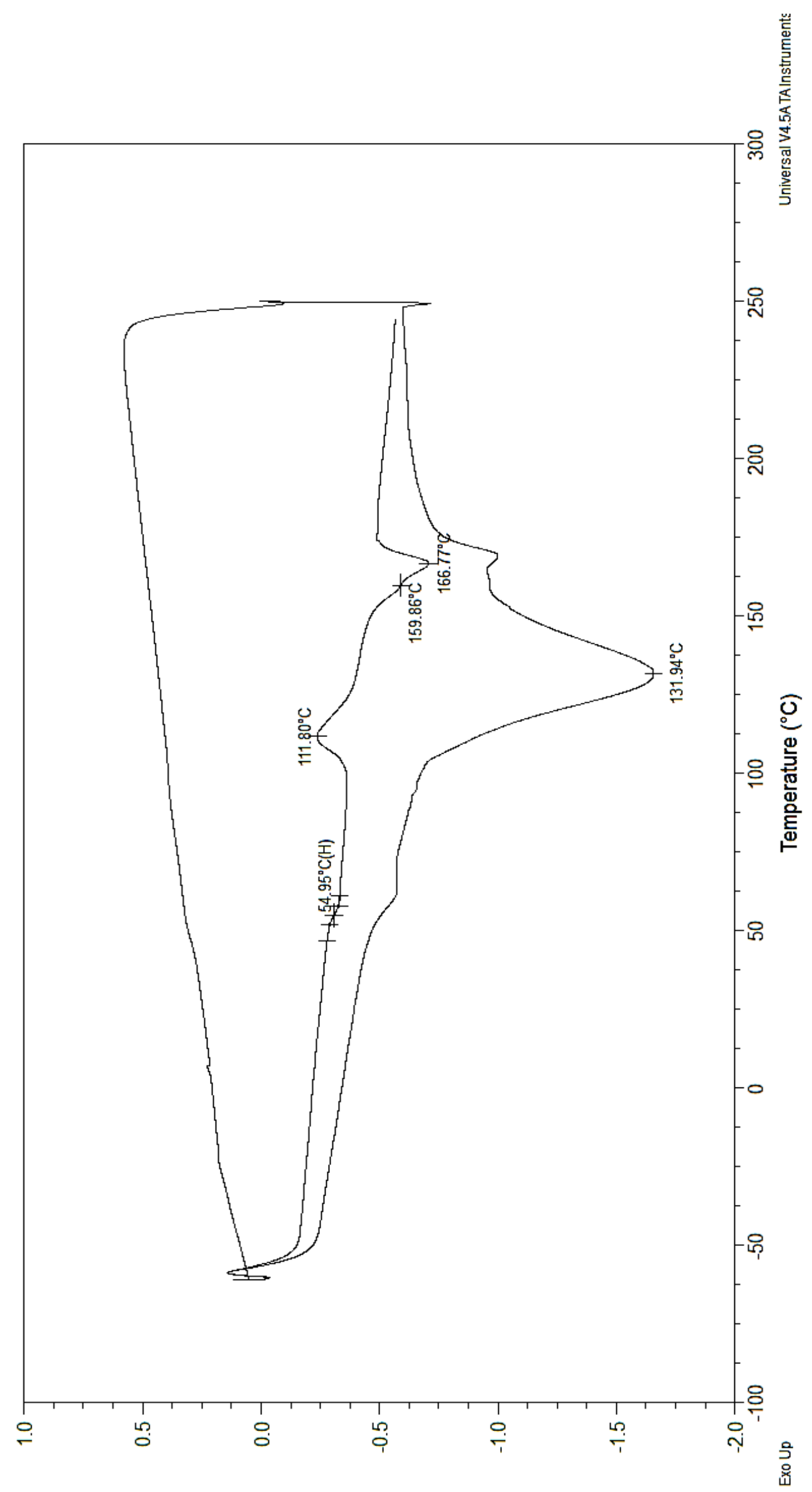

(6/M) MOI

Fig. 1: Curva DSC de BANISN4. 


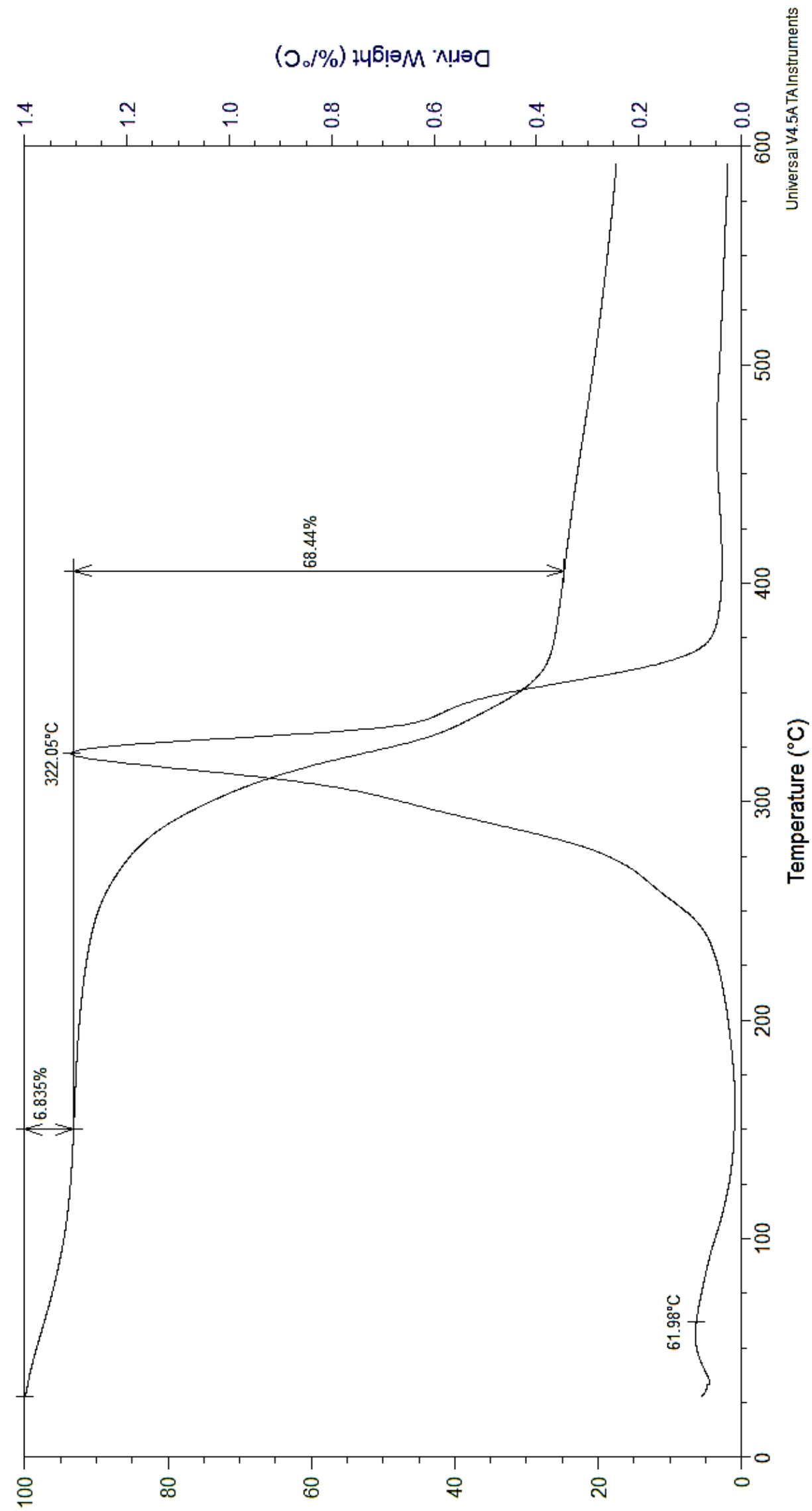

(\%) +4ธิ!๐ $M$

Fig. 2: Curva de medición TGA de BANISN4. 
Asimismo, el almidón cuando es humedecido y se calienta bajo presión forma el almidón termoplástico, un material con pobres propiedades de barrera al agua (Dos Santos et al., 2018). En la tabla 5, se reporta valor promedio \pm desviación estándar. Superíndices diferentes en la misma columna indican diferencias significativas $(p<0,05)$. En la tabla 6 se presentan los valores estadísticos del análisis de varianza.

Tabla 5: Porcentaje de absorción de agua de los biocompuestos.

\begin{tabular}{|c|c|}
\hline Biocompuesto & Absorción de agua (\%) \\
\hline BCONTROL & $145,29 \pm 19,04^{\mathrm{a}}$ \\
\hline BANISN1 & $48,14 \pm 3,83^{\mathrm{b}}$ \\
\hline BANISN2 & $36,84 \pm 4,17^{\mathrm{b}}$ \\
\hline BANISN3 & $39,56 \pm 6,59^{\mathrm{b}}$ \\
\hline BANISN4 & $35,02 \pm 5,61^{\mathrm{b}}$ \\
\hline
\end{tabular}

Tabla 6: Análisis de varianza de la prueba de absorción de agua

\begin{tabular}{|l|c|c|c|c|}
\hline \multicolumn{5}{|c|}{ Absorción de agua } \\
\hline Fuente & $\begin{array}{c}\text { SC } \\
\text { Ajust }\end{array}$ & MC Ajust & Valor F & $\begin{array}{c}\text { Valor } \\
\text { p }\end{array}$ \\
\hline Tratamiento & 44950 & 11237,4 & 115,91 & 0,000 \\
\hline Error & 1939 & 96,9 & & \\
\hline Total & 46889 & & & \\
\hline
\end{tabular}

Las muestras del BA presentaron menor absorción de agua, debido a la naturaleza hidrófoba del PLA (Ghorpade et al., 2001). Hassan et al. (2019), mostraron un efecto similar en muestras elaboras a partir de fibra y PLA. Asimismo Cerón y Villada (2016), reportaron valores similares de absorción de agua en biocompuestos elaborados a partir de harina de yuca y fique recubiertos con colofonia.

\section{Análisis microbiológico}

Las cuatro concentraciones del BA no tienen un efecto antimicrobiano sobre el crecimiento de E. coli. En la figura 3 se puede ver que los tratamientos BCNIS1 y BCNIS4 no presentan inhibición. En investigaciones se reporta el efecto que tiene la nisina sobre bacterias Gram positivas en aplicaciones alimentarias, mas no sobre E. coli, que es una bacteria Gram negativa (Salmieri et al., 2014; Shiroodi et al., 2016). Esto se puede deber a que la E. coli está desarrollando resistencia al antimicrobiano, al ser una bacteria Gram negativa tienen la capacidad de modificar el lípido A que es uno de los principales responsables de la interacción con el sistema inmune innato, ya que activa la respuesta de los TLR4 y su fosfato genera una carga negativa que interactúa con los péptidos antimicrobianos; por lo tanto, al modificar su carga es capaz de resistir la acción bactericida de los péptidos antimicrobianos y evitar una respuesta inmune (Téllez \& Castaño, 2010).
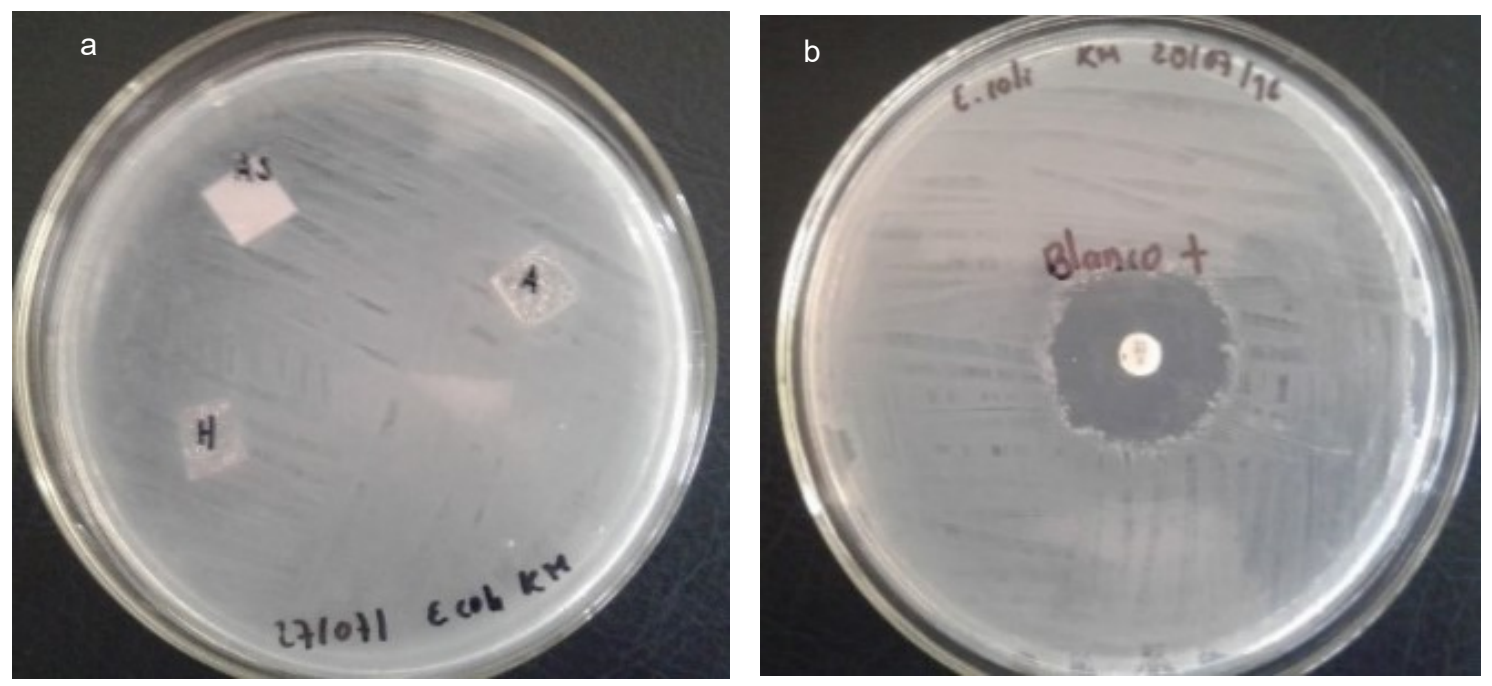

Fig. 3: Prueba de difusión en agar contra E. coli de BA/nisina: a. AS: BCNIS4; A: BCNIS1; H: BCONTROL. b. antimicrobiano comercial gentamicina 
Es decir que el biocompuesto desarrollado, aunque no probó una inhibición sobre una bacteria Gram negativa, abre el camino para la investigación sobre la incorporación de otros antimicrobianos de espectro más amplio, además se comprobó que la capa de PLA permite la inserción de compuestos activos y permite mejorar las propiedades de barrera al agua.

\section{CONCLUSIONES}

De acuerdo a los resultados obtenidos, de su análisis y discusión, se puede obtener las siguientes conclusiones principales: 1) El fin principal de la metodología empleada, radica en una reducción significativa de la absorción de agua; 2) el método propuesto para obtener el biocompuesto se puede escalar, debido a que es posible aplicar operaciones de extrusión y moldeo por compresión; 3) La incorporación de PLA a la matriz de almidón / celulosa mejora las propiedades de barrera, la adición de la nisina no tiene efecto sobre la resistencia a la flexión y módulo de flexión; 4) La adición de PLA en los biocompuestos aumento la Tg, es decir que mejoro la estabilidad térmica, asimismo permitió aumentar la temperatura máxima de degradación térmica; 5) La capa de PLA permitió obtener un biocompuesto con bajo porcentaje de absorción de agua, aspecto que prueba su efectividad para aplicaciones alimentarias con alta humedad; 6) Aunque las concentraciones estudiadas de nisina no tuvieron efecto sobre $E$. coli, el compuesto se logró incorporar en la matriz de PLA, lo que pude ser prometedor para elaboración de empaques activos.

\section{NOTACIÓN}

IP: Incremento del peso de la muestra por la inmersión (\%)

$\mathrm{PH}$ : Peso de la muestra húmeda $(\mathrm{g})$

PA: Peso de la muestra después del acondicionamiento $(\mathrm{g})$

MSP: Material soluble perdido (\%)

PRA: Peso de la muestra después del reacondicionamiento $(\mathrm{g})$

\section{REFERENCIAS}

Anuar, H., Izzati, A. B., y otros 5 autores, Impregnation of Cinnamon Essential Oil into Plasticised Polylactic Acid Biocomposite Film for Active, Food Packaging, https://doi.org/10.1007/s41783-017-0022-1, Journal of Packaging Technology and Research, 1(3), 149-156 (2017)

Bastarrachea, L., Dhawan, S., y otros 5 autores, Biodegradable poly(Butylene adipate-co-terephthalate) films incorporated with nisin: Characterization and effectiveness against Listeria innocua, https://doi.org/10.1111/j.17503841.2010.01591.x, Journal of Food Science, 75(4) (2010)

Battegazzore, D., Alongi, J., y Frache, A., Poly(lactic acid)-Based Composites Containing Natural Fillers: Thermal, Mechanical and Barrier Properties, https://doi.org/10.1007/s10924-013-0616-9, Journal of Polymers and the Environment, 22(1), 88-98 (2014)

Bhat, R., Abdullah, N., Din, R. H., y Tay, G. S, Producing novel sago starch based food packaging films by incorporating lignin isolated from oil palm black liquor waste, https://doi.org/10.1016/j.jfoodeng.2013.06.043, Journal of Food Engineering, 119(4), 707-713 (2013)

Biswaro, L. S., da Costa Sousa, M.G., y otros tres autores, Antimicrobial peptides and nanotechnology, recent advances and challenges, https://doi.org/10.3389/FMICB.2018.00855, Frontiers in Microbiology, 9(May), 855 (2018)

Cajiao, E. S., Bustamante, L. E., Cerón, A. R., y Villada, H. S, Efecto de la Gelatinización de Harina de Yuca sobre las Propiedades Mecánicas Efecto de la Gelatinización de Harina de Yuca sobre las Propiedades Mecánicas, Térmicas y Microestructurales de una Matriz Moldeada por Compresión, https://doi.org/10.4067/S0718-07642016000400006, Información Tecnológica, 27(20) (2016)

Campaña, O., Guerrero., y Guerrero, V.H., Caracterización Mecánica y Térmica de Ácido Poliláctico (PLA) Reforzado con Polvo de Bambú (PB), Revista politécnica, ISSN 2477-8990, 42(1), 8 (2018)

Cerón Mosquera, A. R., y Villada Castillo, H. S, Behavior respect to water of a matrix of cassava flour coated with rosin, Vitae, ISSN: 2145-2660, 23, S217-S221 (2016)

Dos Santos, B. H., De Souza, K., Jacinto, A. A., y Da Silva, M. A, Influence of sugarcane bagasse fiber size on biodegradable composites of thermoplastic starch, https://doi.org/10.7569/JRM.2018.634101, Journal of Renewable Materials, 6(2), 176-182 (2018)

Dos Santos, C. A., dos Santos, G. R., y otros 8 autores, Bacterial nanocellulose membranes combined with nisin: a strategy to prevent microbial growth, https://doi.org/10.1007/s10570-018-2010-1, Cellulose, 25(11), 6681-6689 (2018)

Frone, A. N., Berlioz, S., Chailan, J. F., y Panaitescu, D. M., Morphology and thermal properties of PLA-cellulose nanofibers composites, https://doi.org/10.1016/j.carbpol.2012.08.054, Carbohydrate Polymers, 91(1), 377-384 (2013) 
George, M., Chae, M., y Bressler, D. C, Composite materials with bast fibres: Structural, technical, and environmental properties, https://doi.org/10.1016/j.pmatsci.2016.04.002, Progress in Materials Science, 83, 1-23 (2016)

Ghorpade, V. M., Gennadios, A., y Hanna, M. A, Laboratory composting of extruded poly(lactic acid) sheets, https://doi.org/10.1016/S0960-8524(00)00077-8, Bioresource Technology, 76(1), 57-61 (2001)

Hassan, M. M., Le Guen, M. J., Tucker, N., y Parker, K, Thermo-mechanical, morphological and water absorption properties of thermoplastic starch/cellulose composite foams reinforced with PLA, https://doi.org/10.1007/s10570-01902393-1, Cellulose, 26(7), 4463-4478 (2019)

Jin, T., y Zhang, H., Biodegradable polylactic acid polymer with nisin for use in antimicrobial food packaging, https://doi.org/10.1111/j.1750-3841.2008.00681.x, Journal of Food Science, 73(127)-134 (2008)

Jin, T., Zhang, H., y Boyd, G., Incorporation of Preservatives in Polylactic Acid Films for Inactivating Escherichia coli O157:H7 and Extending Microbiological Shelf Life of Strawberry Puree, doi: 10.4315/0362-028x-73.5.812, Journal Of Food Protection, 73, 812-818 (2010)

Li, W., Liu, L., y Jin, T. Z, Antimicrobial activity of allyl isothiocyanate used to coat biodegradable composite films as affected by storage and handling conditions, https://doi.org/10.4315/0362-028X.JFP-12-234, Journal of Food Protection, 75(12), 2234-2237 (2012)

Martin, O., y Avérous, L., Poly(lactic acid): Plasticization and properties of biodegradable multiphase systems, https://doi.org/10.1016/S0032-3861(01)00086-6, Polymer, 42(14), 6209-6219 (2001)

Plackett, D. V., Holm, V. K., y otros 6 autores, Characterization of L-polylactide and L-polylactide-polycaprolactone copolymer films for use in cheese-packaging applications, https://doi.org/10.1002/pts.704, Packaging Technology and Science, 19(1), 1-24 (2006)

Rajesh, G., Ratna, P. A.V., y Gupta A.V.S.S.K.S., Mechanical and Degradation Properties of Natural Fiber Reinforced PLA Composites: Jute, Sisal, and Elephant Grass Rajesh, https://doi.org/https://doi.org/10.1002/pc.24041, Polymer Composites, 16(2), 101-113 (2016)

Sainia, S., Sillarda, C., Naceur, M., y Bras, J., Nisin anchored cellulose nanofibers for long term antimicrobial active food packaging, https://doi.org/10.1039/C5RA22748H, RSC Advances, 6, 12422-12430 (2016)

Salmieri, S., Islam, F., y otros 6 autores, Antimicrobial nanocomposite films made of poly(lactic acid)-cellulose nanocrystals (PLA-CNC) in food applications: Part A-effect of nisin release on the inactivation of Listeria monocytogenes in ham, https://doi.org/10.1007/s10570-014-0230-6, Cellulose, 21(3), 1837-1850 (2014)

Sánchez-safont, E. L., Aldureid, A., y Lagarón, J. M., Biocomposites of different lignocellulosic wastes for sustainable food packaging applications, https://doi.org/10.1016/j.compositesb.2018.03.037, Composites Part B, 145(1), 215-225 (2018)

Santiagoo, R., Ismail, H., y Hussin, K., Mechanical properties, water absorption, and swelling behaviour of rice husk powder filled polypropylene/recycled acrylonitrile butadiene rubber ( $\mathrm{pp} / \mathrm{nbrr} / \mathrm{rhp}$ ) biocomposites using silane as a coupling agent, https://doi.org/10.15376/biores.6.4.3714-3726, BioResources, 6(4), 3714-3726 (2011)

Shiroodi, S. G., Nesaei, S., y otros 4 autores, Biodegradable Polymeric Films Incorporated with Nisin: Characterization and Efficiency against Listeria monocytogenes, https://doi.org/10.1007/s11947-016-1684-3, Food and Bioprocess Technology, 9(6), 958-969 (2016)

Tan, M. Y., Kuan, H. T., y Lee, M. C., Characterization of Alkaline Treatment and Fiber Content on the Physical, Thermal, and Mechanical Properties of Ground Coffee Waste/Oxobiodegradable HDPE Biocomposites, https://doi.org/10.1155/2017/6258151, International Journal of Polymer Science (2017)

Tawakkal, I. S. M. A., Cran, M. J., Miltz, J., y Bigger, S. W., A review of poly(lactic acid)-based materials for antimicrobial packaging, https://doi.org/10.1111/1750-3841.12534, Journal of Food Science, 79(8) (2014)

Téllez, G.A., y Castaño, J. C., Péptidos antimicrobianos Antimicrobial peptides, https://doi.org/10.1016/S01239392(10)70093-X, Infectio Asociación Colombiana de Infectología, 14(1), 55-67 (2010)

Yew, G. H., Mohd Yusof, A. M., Mohd Ishak, Z. A., y Ishiaku, U. S., Water absorption and enzymatic degradation of poly(lactic acid)/rice starch composites, https://doi.org/10.1016/j.polymdegradstab.2005.04.006, Polymer Degradation and Stability, 90(3), 488-500 (2005)

Zhong, Y., Godwin, P., Jin, Y., y Xiao, H., Biodegradable polymers and green-based antimicrobial packaging materials: A mini-review, https://doi.org/10.1016/j.aiepr.2019.11.002, Advanced Industrial and Engineering Polymer Research, 3(1), 27-35 (2020) 